\title{
Pseudoxanthoma elasticum: A review of 86 cases in China
}

\author{
Yan $\mathrm{Li}^{1,2}$, Yazhou Cui ${ }^{1}$, Heng Zhao ${ }^{1,2}$, Chao Wang ${ }^{1,2}$, Xiao Liu ${ }^{1,2}$, Jinxiang Han ${ }^{1, *}$ \\ ${ }^{1}$ Key Laboratory for Biotech Drugs of the Ministry of Health, Key Laboratory for Rare Disease of Shandong Province, Shandong \\ Medicinal Biotechnology Center, Shandong Academy of Medical Sciences, Ji'nan, Shandong, China; \\ ${ }^{2}$ School of Medicine and Life Sciences, University of Jinan-Shandong Academy of Medical Science, Ji'nan, Shandong, China.
}

\begin{abstract}
Summary Pseudoxanthoma elasticum (PXE) is a type of rare hereditary disease that affects connective tissue. PXE is found around the world, and its epidemiology in China is still unclear. A database search revealed that 86 patients in total were reported in China from 1985 to 2013. The vast majority of these reports concern single, sporadic cases. This review summarizes the clinical characteristics of PXE and its treatment in China. The hope is to provide a reliable basis for studies on the incidence of PXE and for formulation of relevant policies in the future.
\end{abstract}

Keywords: Rare diseases, prevalence, clinical features, literature search

\section{Introduction}

Pseudoxanthoma elasticum (PXE) is a type of rare hereditary disease that affects connective tissue, causing mineralization of elastic fibers in the skin, eyes, cardiovascular system, and even the digestive system. A typical clinical manifestation of PXE is the appearance of small (one to five millimeters), asymptomatic, soft papules that are yellow/ivory in color on the flexural surfaces (1). Skin signs are typically followed by ocular signs, which include angioid streaks, choroidal neovascularization, and subretinal hemorrhaging that result in loss of visual acuity and occasionally lead to blindness. Cardiovascular signs include a pulse that is weak or even absent and intermittent claudication. A few patients may have angina pectoris or hypertension. The disease is often accompanied by gastrointestinal symptoms that may lead to severe joint problems and gastrointestinal bleeding. Statistical analysis has indicated that the incidence of the disease is about one in 50,000 (2). The disease affects women more often than men at a ratio of $2: 1$. The main pathological changes in the skin are the degeneration, swelling,

\footnotetext{
*Address correspondence to:

Dr. Jinxiang Han, Key Laboratory for Rare Disease Research of Shandong Province, Key Laboratory for Biotech Drugs of the Ministry of Health, Shandong Medical Biotechnological Center, Shandong Academy of Medical Sciences, Ji'nan, Shandong 250062, China.

E-mail: samshjx@sina.com
}

rupturing, and mineralization of elastic fibers. The molecular basis of PXE remains unknown, but the disease is caused by mutations in the ABCC6 gene encoding an ATP-dependent transmembrane transporter, the substrate and pathophysiological role of which have yet to be elucidated (3). In light of its genetic features, inheritance of PXE is usually divided into autosomal dominant inheritance or autosomal recessive inheritance. Based on the severity of the condition, each variant of PXE is divided into type I (typical or severe) or type II (atypical or light) disease. The autosomal recessive form of the disease is often characterized by metabolic abnormalities. Thus far, researchers have yet to identify any specific therapy for the disease, and PXE is often treated symptomatically. Surgery can be performed to remove lax skin hanging in folds, and vitamin E may be used to treat fundus retinopathy (4). The current article briefly reviews the current state of PXE epidemiology, diagnosis, and treatment in China.

\section{Literature search strategy}

The Wanfang Database and China National Knowledge Infrastructure Database were searched using the keyword "Pseudoxanthoma elasticum" along with "diagnosis" or "treatment" or "epidemiology" to identify all relevant literature published in Chinese journals from January 1985 to April 2013. Cases of PXE with a confirmed diagnosis were included. Studies including keywords like angioid streaks were also noted and then examined for mention of PXE. The full text of 
each article was reviewed and the article was selected if relevant. Each patient's medical information was carefully compared and repeated cases were excluded.

\section{Prevalence and epidemiology}

\subsection{Prevalence and epidemiology}

A search of articles on PXE in the databases indicated that 86 patients in total have been reported in China from 1985 to 2013. In total, 19 men and 67 women were affected by PXE according to reports in China, as shown in Figure 1A. Women were affected more often than men at a ratio of $3.53: 1$. The patient age at the time of diagnosis ranged from 8 to 72 years; 4 patients were under 10 (4.6\%), 18 patients were ages 10-19 (21\%), 31 patients were ages 20-29 (36\%), and 33 patients were age 30 or older (38.4\%) (Figure 1B). PXE was found in
20 provinces and cities in China. Data showed that the incidence was significantly higher in Shanxi Province than in other areas (Figure 1C). This may be related to the local level of medical care. Six of the patients in the literature had a family history of PXE; 3 patients had autosomal dominant type I disease (5-7) while 3 patients had autosomal recessive type I disease (8-10).

\subsection{Clinical manifestations of PXE in Chinese patients}

All patients present with characteristic skin lesions of yellowish papules that coalesce into plaques. Skin is inelastic and leathery but does not otherwise cause discomfort. The lesions of PXE are typically distributed in intertriginous sites of the body, in other words in the folds of the skin at the sides of the neck, the joints of the limbs, the axillae, the cubital and popliteal fossae, and the creases of the groin and umbilical region. The
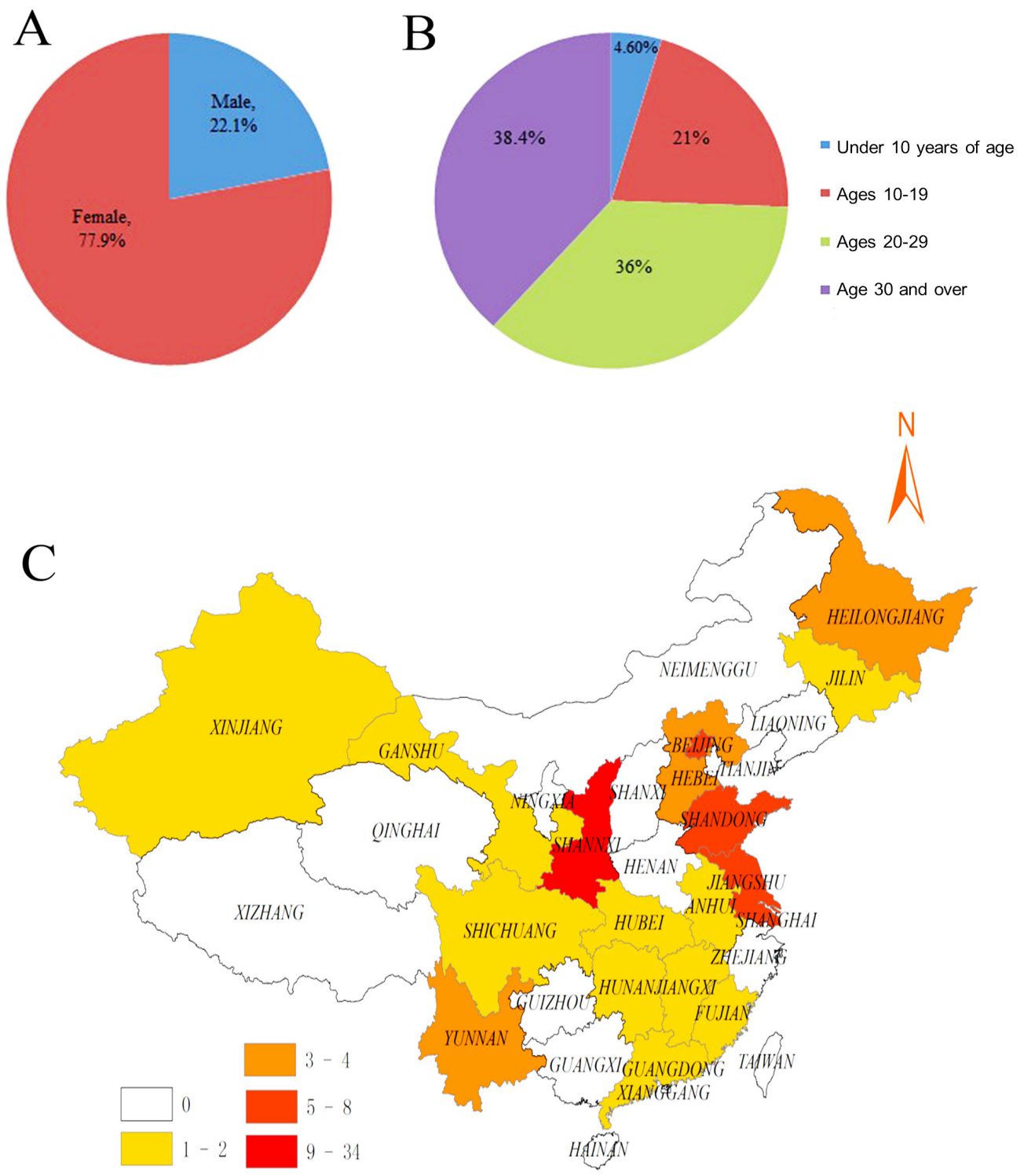

Figure 1. Prevalence and epidemiology according to Chinese case reports. (A), Proportion of men and women affected; (B), Age of patients; (C), Geographical distribution of PXE case reports in China. 
onset and duration of the cutaneous lesions of PXE vary. Women noticed abnormal skin at an average age of 22 . However, only 5 men were aware of the duration of changes in their skin. This difference in awareness is possibly related to the greater attention that women give to the appearance of the skin on the exposed parts of the body compared to men.

Of 86 patients with PXE, 55 underwent a fundus examination and 21 had angioid streaks originating from the optic disc that radiated outwards as brownishgrey irregular lines. About a fourth of the affected patients had maculopathy while only two patients had a subretinal hemorrhage $(11,12)$. Lesions are generally asymptomatic unless they extend into the macula.

Six patients had different degrees of gastrointestinal bleeding. Two had bleeding from the large intestine $(13,14)$ and two had involvement of the gastric mucosa $(15,16)$. The remaining two patients had internal hemorrhoids that were not serious $(10,17)$. Hypertension was present in two of the patients with PXE (16,17). Some researchers have noted patients with PXE have a markedly higher incidence of hypertension than normal persons (18). Only one of the 86 patients (a 75-year-old woman) had clinically evident myocardial infarction (19) and another woman suffered specific cardiomyopathy (20). One patient had PXE with hyperthyroidism for three years (21). Chen et al. reported a 30-year-old female patient with typical pathological changes in the skin and eyes who was at risk of a spontaneous abortion in the first 3 months of both her pregnancies, but they were unable to determine whether the risk of spontaneous abortion was related to PXE (22). Various complications noted in the 86 patients with PXE are shown in Figure 2.

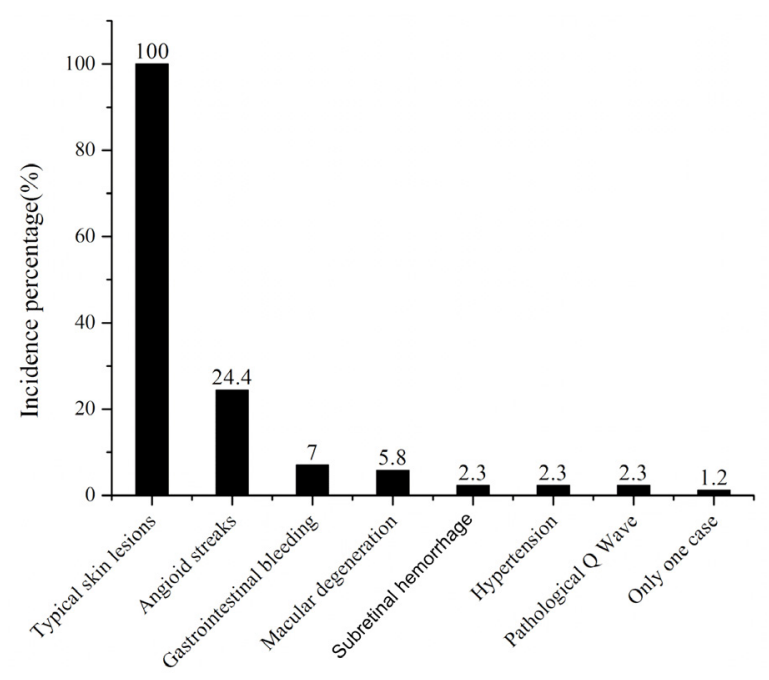

Figure 2. Percentage of various complications. Myocardial infarction, specific cardiomyopathy, aortic fibrosis, right ventricular hypertrophy, coronary artery stenosis, hematuria, premature ventricular contractions, short P-R interval syndrome, mitral inadequacy, hyperthyroidism, and atrial premature contraction were noted in "only one case."

\section{Discussion}

The main diagnostic criteria for PXE include $i$ ) small, yellowish, flat papules that typically develop on the skin of the neck, axillae, groin, and flexural creases; ii) angioid streaks, which are irregular, reddishbrown, or grey lines that radiate from the optic disc; iii) histological characteristics of PXE skin lesions with fragmentation and calcification of mid-dermal elastic fibers on Alizarin red staining. A histological examination of the skin is still the gold standard for diagnosing PXE (23). Almost all patients met the first and third criteria. Only 21 patients had angioid streaks since the disease had taken a different course. All patients were diagnosed based on a skin biopsy.

\section{Treatment}

Based on Chinese reports, doctors symptomatically treat patients with PXE. Limiting dietary calcium intake may reduce the progression of lesions and laser photocoagulation should be performed early on when the macula lutea is affected by angioid streaks. Oral vitamin E can be used to treat ocular symptoms. Only one case report mentioned a 19-year-old female patient with PXE who underwent repair of loose skin of the face and neck, and this is the first such case reported in China (24). Some researchers administered oral phosphate binders to 6 patients and they noted marked improvement in clinical symptoms in 3 of those patients (25). Moreover, the histopathological changes in lesions gradually disappeared. In a 1-year follow-up, no patients had further eye damage. The current review is key to guiding the treatment of PXE. However, the current findings must be studied further since the sample size was too small.

\section{Conclusion}

PXE is a type of rare disease, and little is known about its epidemiologic characteristics in China. A literature search revealed that there are more studies and case reports on PXE in Europe and the United States than in China. Researchers conducted a study of 513 patients to determine the effect of gender on PXE, and they found that gender differences were statistically significant (26). A literature search revealed that only 86 cases of PXE have been reported in China, and no studies of patients with PXE have been conducted. This greatly hampers an analysis of the clinical features and epidemiological characteristics of patients with PXE in China. In addition, complications of PXE are detected at a higher rate in developed countries than in China. This may relate to the earlier start of PXE research and the establishment of case databases. To the extent known, this is the first systematic review of the incidence of PXE in China. The current state of PXE diagnosis and treatment in China is 
unsatisfactory. The low incidence rate does not coincide with the country's large population, indicating that the clinical outlook is bleak. To date, there are no specific pharmacological therapies for PXE. In 2013, China launched its first pilot project covering 20 representative rare diseases in order to improve conditions. PXE is one of the 20 rare diseases (27). The current review can help to further elucidate the current state of PXE in China and encourage more statistical research. This review seeks to provide a reliable basis for researchers to diagnose, treat, and study PXE and formulate relevant policies in accordance with conditions in China.

\section{References}

1. Georgalas I, Tservakis I, Papaconstaninou D, Kardara M, Koutsandrea C, Ladas I. Pseudoxanthoma elasticum, ocular manifestations, complications and treatment. Clin Exp Optom. 2011; 94:169-180.

2. Uitto J, Bercovitch L, Terry SF, Terry PF. Pseudoxanthoma elasticum: Progress in diagnostics and research toward treatment: Summary of the 2010 PXE International Research Meeting. Am J Med Genet A. 2011; 155:1517-1526.

3. Li Q, Jiang Q, Pfendner E, Váradi A, Uitto J. Pseudoxanthoma elasticum: Clinical phenotypes, molecular genetics and putative pathomechanisms. Exp Dermatol. 2009; 18:1-11.

4. Zhao B. Chinese Clinical Dermatology. 3rd ed., Jiangsu Science and Technology Press, NanJing, China, 2010; pp. 1110-1112. (in Chinese)

5. Mu DM, Zhou GZ. A case of pseudoxanthoma elasticum with skin penetration. Chinese Journal of Dermatology. 1995; 28:118. (in Chinese)

6. Fu P, Long FQ, Chen H. A case of pseudoxanthoma elasticum with nevus of Ota. Chinese Journal of Clinical Dermatology. 2004; 33:564-565. (in Chinese)

7. Hu Y, Wang GJ, Li T, Dong DK, Zhang HQ, Chen LY. A family report of PXE with freckles. Chinese Journal of Clinical Dermatology. 2010; 39:180-181. (in Chinese)

8. Yu YC, Guo ZL, Yang QG, Zheng XD. A family report of two PXE cases. Chinese Journal of Clinical Dermatology. 2004; 33:502. (in Chinese)

9. Shi XQ, Chen WF, Liu XP. Sisters suffering from pseudoxanthoma elasticum. Journal of Clinical Dermatology. 2007; 36:311-312. (in Chinese)

10. Yan JH, Yu LT, Tang YC, Zhang MH. A case of pseudoxanthoma elasticum. China Journal of Leprosy and Skin Diseases. 2011; 27:204. (in Chinese)

11. Zhang XH, Jin XZ, Liu JH. A case of pseudoxanthoma elasticum. Journal of Jinling Hospital. 1992; 5:229. (in Chinese)

12. Wang HS. Two cases of angioid streaks. Medical Journal of National Defending Forces in Southwest China. 1996;
6:313-314. (in Chinese)

13. Yan XX, Zhang DC, Chen SL, Yu ML. A case of pseudoxanthoma elasticum. China J Lepr Skin Dis. 2008; 24:990. (in Chinese)

14. Wang CZ, Liu YS, Yang L. A case of pseudoxanthoma elasticum. China Journal of Leprosy and Skin Diseases. 2011; 27:505-506. (in Chinese)

15. Wang XB, Luo LH, Xue W. A case of pseudoxanthoma elasticum. International Journal of Dermatology and Venereology. 2008; 34:217. (in Chinese)

16. Zou WY. A case of pseudoxanthoma elasticum accompanied by angioid streaks. Acta Universitatis Medicinae Tongji. 1987; 4:295-296. (in Chinese)

17. Chang DQ, Wang WL, Li L. A case of pseudoxanthoma elasticum. The Chinese Journal of Dermatovenereology. 2008; 22:752. (in Chinese)

18. Crespi G, Derchi LE, Saffioti S. Sonographic detection of renal changes in pseudoxanthoma elasticum. Urol Radiol. 1992; 13:223-225.

19. Cheng Y, Wang BN, Wu MZ. A case of pseudoxanthoma elasticum with myocardial infarction. Linchuang Huicui [Clinical Focus]. 2007; 22:821. (in Chinese)

20. Zhou LJ, Guo WB, Mao WZ. A case of pseudoxanthoma elasticum with specific cardiomyopathy. Chinese Journal of Dermatology. 1985; 18:110-111. (in Chinese)

21. Wu ZS, Jin L, Ma DL, Yan H, Geng SM, Chen LQ, Tan DY, Li Y, Yuan W, Yan TK, Yang LT, Zhang W, Wang G. Clinical and pathological analysis of 29 cases of pseudoxanthoma elasticum. Chinese Journal of Dermatology. 2013; 46:698-701. (in Chinese)

22. Chen XY, Zhang HR, Wang W. A case of pseudoxanthoma elasticum. Chinese Journal of Ophthalmology. 2004; 40:275-277. (in Chinese)

23. Hosen MJ, Lamoen A, De Paepe A, Vanakker OM. Histopathology of pseudoxanthoma elasticum and related disorders: Histological hallmarks and diagnostic clues. Scientifica (Cairo). 2012; 2012:598262.

24. Plastic surgery in the treatment of pseudoxanthoma elasticum (http://cpfd.cnki.com.cn/Article/CPFDTOTALZJKX200703001417.htm) (accessed May 20, 2014). (in Chinese)

25. Sherer DW, Singer G, Uribarri J, Phelps RG, Sapadin AN, Freund KB, Yanuzzi L, Fuchs W, Lebwohl M. Oral phosphate binders in the treatment of pseudoxanthoma elasticum. J Am Acad Dermatol. 2005; 53:610-615.

26. Uitto J, Váradi A, Bercovitch L, Terry PF, Terry SF. Pseudoxanthoma elasticum: Progress in research toward treatment: Summary of the 2012 PXE International Research Meeting. J Invest Dermatol. 2013; 133:14441449.

27. Cui Y, Zhou X, Han J. China launched a pilot project to improve its rare disease healthcare levels. Orphanet J Rare Dis. 2014; 9:14.

(Received June 5, 2014; Revised August 7, 2014; Accepted August 26, 2014) 